ISSN: $1130-3743$

\title{
REFLEXIONES SOBRE CULTURA, IDENTIDAD Y RACISMO DESDE UNA MIRADA PEDAGÓGICA
}

\author{
Reflections about culture, identity and racism from a \\ pedagogical glance
}

\section{Quelques réflexions sur culture, identité et racisme depuis un regard pédagogique}

Pilar ARNÁIz SÁNCHEZ* y Andrés ESCARBAJAL FRUTOS***

Universidad de Murcia. Facultad de Educación. Departamento de Didáctica

y Organización Escolar. Campus de Espinardo. 30100 Murcia.

Correo-e:"parnaiz@um.es, ***andreses@um.es

Fecha de recepción: marzo de 2012

Fecha de aceptación definitiva: julio de 2012

Biblid [(1130-3743) 24, 2-2012, 83-106]

RESUMEN

Históricamente en nuestro contexto siempre han existido comunidades con diferencias culturales, pero nunca se había dado un fenómeno pluricultural de manera tan rápida y masiva, como en la fase histórica actual, que haya ocasionado la aparición de actitudes y episodios de xenofobia y racismo tan significativos. Por ello, en el presente artículo hacemos un análisis de conceptos que nos parecen fundamentales para explicar esta situación, como son los de cultura, identidad y racismo, y destacamos cómo los procesos de globalización deberían permitir interpretar las diferentes culturas en tanto realidades abiertas. Del mismo modo, defendemos que la identidad cultural debe ser considerada dentro de una constelación de identidades particulares y no ser entendida como refugio etnocéntrico. Finalmente enfatizamos la importancia de la educación intercultural como educación para la ciudadanía, educación para la inclusión y la participación ciudadana. 
Palabras clave: cultura, identidad, racismo, educación intercultural, educación para la ciudadanía, inclusión, participación ciudadana.

\section{SUMMARY}

Throughout our history there have always been communities with cultural differences in our country. We have never before, however, experienced such a fast and massive multicultural phenomenon as there is in our current historical period, which has resulted in the emergence of highly significant xenophobic and racist attitudes and episodes. This article analyses, therefore, the fundamental concepts that seem to explain this situation, such as culture, identity and racism, and highlights how globalisation processes should allow us to understand different cultures. Similarly, we argue that cultural identity should be included within a constellation of self-identities and not be seen as an ethnocentric shelter. Finally, we emphasise the importance of intercultural education, such as citizenship education, education for inclusion and citizen participation

Key words: culture, identity, racism, intercultural education, citizenship education, citizen participation.

\section{SOMMAIRE}

D'un point de vue historique dans notre contexte on avait toujours communautés avec des différences culturales mais jamais on a avait des phénomènes culturelles aussi rapide et massive, comme dans le moment historique actuel, qui on ait produise l'apparition des épisodes de xénophobie et racisme avec tante signification. Ce pour cela que dans cet article nous façons un analyse des conceptions que nous semblent fondamentaux pour expliquer ce situation, comme sont la culture, l'identité et le racisme, et en plus nous mettrons en place comment les processus de globalisation devraient permettre l'interprétation des différentes cultures en tant que réalités ouvertes. Ainsi nous défendons que l'identité culturelle doive être considérée dedans d'une constellation d'identités particulières et non doit être considérée comme un refugie ethnocentrique. Finalement, nous mettrons l'emphase dans l'importance de l'éducation interculturelle comme une éducation pour la citoyenneté, une éducation pour l'inclusion et pour la participation citadine.

Mots clés: culture, identité, racisme, éducation interculturelle, éducation par la citoyenneté, participation citadine.

Lo que hace que yo sea yo, y no otro, es estar en las dos lindes de dos países, de dos o tres idiomas, de varias tradiciones culturales. Es eso justamente lo que define mi identidad. Amin MAalouf (2008) 


\section{INTRODUCCIÓN}

La llamada civilización occidental es deudora de las aportaciones de Babilonia, Egipto, la Grecia clásica, Roma, los grandes pensadores árabes y judíos, como Averroes, Avicena, Ibn Arabí o Maimónides...; por tanto, hablar de lo que es o significa actualmente Europa es reconocer la influencia de todas las comunidades y culturas que han vivido y viven entre nosotros (Eliot, 2003). A pesar de ese reconocimiento es indudable que, desde hace aproximadamente una década, asistimos en nuestro contexto occidental a una gran revolución en los modos de pensar y actuar, de relacionarnos con los otros, que engloba todos los ámbitos de nuestra existencia (Giddens, 2000). Entre otras razones, porque el mundo (y especialmente la sociedad europea) es cada vez más plural y complejo, como consecuencia de la inmigración y el consiguiente aumento de la diversidad en la composición cultural de los grupos humanos.

Sin duda, ello ha determinado que nuestra cultura, nuestra escala de valores y nuestra convivencia hayan sido afectadas de alguna manera. En el caso concreto de España, no es que la situación de diversidad cultural sea nueva, porque históricamente han convivido varias culturas en nuestro país, pero nunca se había dado una situación de pluriculturalidad de manera tan heterogénea como se da en la actualidad, ni el fenómeno se había dado en tan poco tiempo. La transformación operada en España es realmente espectacular: mientras que en la última década del pasado siglo xx una de cada sesenta personas que habitaban en nuestro país era inmigrante, lo que suponía un porcentaje inferior al $2 \%$, ahora, acabada la primera década del siglo xxI, es inmigrante el 10\% de la población; concretamente, según los datos del Ministerio de Trabajo e Inmigración (2010), el número total de inmigrantes era de 4.926.608.

Así, aunque han existido siempre comunidades con diferencias culturales, nunca como en la fase histórica actual de las globalizaciones los encuentrosdesencuentros acaecen de una manera tan drástica y continua, por lo que se hace del todo necesario trabajar desde todos los ámbitos sociales, incluido el educativo naturalmente, para plantear, frente a un mundo en el que los más poderosos quieren imponer sus categorías culturales, la posibilidad de una res pública mundial, un espacio de derechos y deberes compartidos, un proyecto de civilización en la época de la mundialización donde nadie se sienta excluido por su cultura de procedencia; un proyecto de civilización en el que la identidad no sea causa de división entre las personas y tanto el racismo biológico como el cultural desaparezcan.

En este sentido, Beuchot (2004) expone que hay algo universal o general en el ser humano que comparte con las demás culturas, a la vez que hay también diferencias culturales que dan sentido y riqueza a la existencia; sería como un pluralismo bien planteado, ecléctico y mestizo, como el que se da en la mayoría de las culturas. Esta postura intenta preservar las diferencias culturales en el seno de una sociedad, con la obligación de ponerlas sobre la mesa para intentar establecer consensos con personas que tienen otras culturas y presentan diferentes visiones 
de la vida. Dicho de otro modo, para no aislar a ningún grupo cultural, sino para abrir a todos los grupos a la crítica y al contacto con los demás. Se trata, pues, de no renunciar a la propia identidad, de forma que ésta no impida la convivencia en la diversidad; y ello teniendo en cuenta lo que expresa Cambi (2010): la ciudadanía en la época de la globalización es una cuestión política, sin olvidar que también es una cuestión educativa fundamental.

A tenor de lo dicho, en el presente artículo analizaremos los conceptos de cultura e identidad y expondremos cómo, según sean entendidos, pueden dar lugar a posturas próximas al racismo y a la xenofobia. Del mismo modo, enfatizaremos la importancia de la educación para paliar o eliminar esas actitudes tan negativas en las sociedades multiculturales. Ampliaremos estas ideas en los siguientes epígrafes.

\section{LA CULTURA}

Genéricamente, los diccionarios y enciclopedias al uso muestran que el término cultura hace referencia al efecto de cultivar los conocimientos humanos y al conjunto de producciones de una comunidad. Si queremos ampliar esta concepción genérica, podemos acudir a la antropología, la cual dirá que cultura es un conjunto de elementos, materiales e inmateriales, con los que un grupo humano se interrelaciona con su entorno, se adapta a él y lo modifica; elementos que son socialmente construidos y asimilados que caracterizan y diferencian a las diversas comunidades (White, 1992). Y, desde concepciones más sociocríticas, también es de interés considerar la definición de Marcuse (1970, 87) quien manifiesta que: "cultura es un proceso de humanización que se caracteriza por el esfuerzo colectivo para proteger la vida humana, mitigar la lucha por la existencia, encuadrándola dentro de unos límites soportables, estabilizar una organización productiva de la sociedad, desarrollar las facultades intelectuales del hombre y reducir o purificar las agresiones, la violencia y la miseria".

Tradicionalmente la cultura se ha entendido como un conjunto de conocimientos y competencias cognitivas generales, así como por los modos de vida de una comunidad concreta. Con el devenir del tiempo, este concepto caminó hacia un enfoque más global y dinámico, que considera las actitudes, valores, creencias y conocimientos ampliamente compartidos en el seno de una sociedad. Conocimientos que se transmiten de generación en generación (Sánchez y Ordóñez, 1997), hasta llegar a las concepciones más aceptadas actualmente, emanadas fundamentalmente de diversos encuentros sobre el concepto de cultura auspiciados por la UNESCO (Gombrich, 2004), como veremos más adelante. En este sentido, y según Bueno (1996), el término cultura comenzó designando una propiedad subjetiva, semejante a educación o formación, que acabó transformándose y adquiriendo un significado más objetivo al ser entendida la cultura como conjunto de cosas valiosas, que unen a los grupos sociales en torno a realidades objetivas.

Para conocer mejor ese cambio, haremos un breve recorrido por algunas de las concepciones de cultura más usuales, comenzando por la clásica definición de Tylor 
(1871, 1; 1995, 29) inserta en la primera página de su conocido libro Primitive Culture: "La cultura o civilización, en sentido etnográfico amplio, es aquel todo complejo que incluye el conocimiento, las creencias, el arte, la moral, el derecho, las costumbres y cualesquiera otros hábitos o capacidades adquiridas por el hombre en cuanto miembro de la sociedad". Por su parte, Kroeber y Cluckhoholm (1952, 283), tras revisar un número aproximado de 200 definiciones de diferentes autores sobre cultura, elaboraron una propia que pretendía ser la síntesis de todas ellas:

La cultura consiste en pautas de comportamiento explícitas o implícitas, adquiridas y transmitidas mediante símbolos y constituye el patrimonio singularizador de los grupos humanos, incluida su plasmación en objetos; el núcleo central de la cultura son las ideas tradicionales (históricamente generadas y seleccionadas) y, especialmente, los valores vinculados a ellas; los sistemas de culturas pueden ser considerados, por una parte, como productos de la acción y, por otra, como elementos condicionantes de la acción futura.

La cultura, escribió Malinowski (1981, 35-36), «es un gran instrumento que permite al hombre afrontar los problemas concretos y precisos que se le plantean en un espacio dado; comprende artefactos, bienes, procesos técnicos, ideas, hábitos y valores heredados que dan a un grupo humano la posibilidad de resolverlos". Por eso, este autor definió la cultura en relación al metabolismo humano (referido tanto a alimento como a la influencia que éste tiene en el tamaño y lugar donde se habita), supervivencia física (sobrevivir frente a otros y al medio), reproducción (comportamiento sexual, división de roles familiares y jerarquía), salud (comportamientos saludables y no saludables) y confort (comodidad y bienestar).

En los años ochenta, en un encuentro promovido por la UNESCO en México (1982), se definió la cultura como el modo en que una comunidad organiza y clasifica la realidad, usa símbolos específicos para comunicarse y tiene determinados modos de comportamiento sujeto a normas específicas que son compartidas por todos los miembros de una comunidad. Su fin es crear sistemas sociales integrados e interrelacionados con gran capacidad de adaptabilidad. En el futuro las nuevas definiciones de cultura se inspirarán en esas pautas elaboradas por la UNESCO. Un ejemplo de ello lo encontramos en la concepción de cultura aportada por Camilleri (1985, 25) al definirla como:

El conjunto más o menos interrelacionado de los significados adquiridos, los más persistentes y los más compartidos, que los miembros de un grupo, por su afiliación a ese grupo, son llevados a distribuir de forma prevaleciente sobre los estímulos procedentes de su entorno y de ellos mismos. Estos estímulos inducen a unas actitudes, unas representaciones y unas conductas comunes valoradas, que tienden a asegurar su reproducción por vías no genéticas.

La propia UNESCO en Estocolmo (1998), siguiendo la tendencia anterior, define la cultura como un conjunto de rasgos distintivos, espirituales y materiales, intelectuales y afectivos que caracterizan a una sociedad o a un grupo social. Éstos abarcan, 
además de las artes y las letras, los modos de vida, la manera de vivir juntos, los sistemas de valores, las tradiciones y las creencias. Así, el concepto se ampliaba en relación a las visiones tradicionales y se tornaba más complejo y dinámico. A partir de este momento la expresión "aprender a vivir juntos" toma un significado especial en relación a las sociedades multiculturales, fundamentalmente aquellas que no tenían tradición de inmigración. La propia unESCO (2003) titulaba de esa manera uno de sus encuentros, orientado a la convivencia escolar en situaciones de pluriculturalidad.

Lo que parece evidente es que, debido a la gran cantidad de concepciones sobre cultura que se han dado históricamente, y teniendo en cuenta la evolución de la misma, podemos entender la dificultad de adoptar una definición que sea comúnmente aceptada en ciencias sociales (Cuché, 1999). Y la dificultad se acrecienta si, como dice Luhmann (1997), consideramos la diversidad de campos que abarca: símbolos, acciones, normas, valores..., puestos en evidencia en las definiciones anteriores; y si además, señala este autor, se añade el concepto de cultura entroncado con la biología (comportamientos aprendidos y transmitidos genéticamente), entonces ya sería francamente difícil establecer límites al concepto, aunque las concepciones científicas más actuales (Mosterín, 2009) hagan hincapié en la información transmitida por aprendizaje social, en contraposición a la información transmitida genéticamente. En todo caso, lo más común es hacer una elección, de manera explícita o implícita, entre dos concepciones generales de cultura, reificada la una y narrativa la otra; elección que produce efectos relevantes tanto en el plano teórico como en el metodológico y práctico, en la manera de entender la educación intercultural, sobre el modo de entender las diferencias y sobre la manera de afrontarlas desde la educación (Mantovani, Schiavinato y Cottone, 2006).

Efectivamente, la concepción reificada de cultura, la dominante tradicionalmente en la literatura científica, nos dice que cada cultura es una realidad homogénea, bien delimitada y definida por características fácilmente reconocibles. De este modo, hablamos de "la cultura árabe" o de "la cultura japonesa" y, para referirnos a las personas de esas culturas, normalmente utilizamos expresiones como: "los árabes", "los japoneses"..., como si todas esas personas fuesen iguales en sus formas de ser y actuar. Se exalta la cultura propia como "pura" y se fomenta la segregación. Ésta sería la base de la actitud del multiculturalismo: respeto a cada cultura, a sus características particulares, pero cada uno ocupando su espacio concreto, sin posibilidad de intercambio cultural. Por el contrario, la concepción narrativa se presenta como alternativa a la anterior, pues entiende la cultura como una construcción que se realiza en la práctica cotidiana de la convivencia entre personas. Antes que la homogeneidad, se valora la interacción, las "zonas de intercambio", y desaparecen las "zonas fronterizas". La cultura es entendida como narración negociada entre personas de diversa procedencia, una narrativa polifónica en la que pueden participar todos (Mantovani, Schiavinato y Cottone, 2006).

En cualquier caso, y de acuerdo con Abdallah-Pretceille (2006), una autora imprescindible en estas temáticas, las diversas acepciones de cultura que se usan 
no pueden dar cuenta de la diversidad cultural contemporánea. La cultura pensada en términos de estructura, de sistema o de categoría no es ya válida, porque conduce a situaciones estáticas, a la categorización o a la noción de diferencia. Así es porque nosotros también creemos que el proceso de categorización opera sobre criterios no muy relevantes: nombre, apariencia, costumbres, folclore..., olvidando que las culturas son construcciones híbridas dinámicas.

Por eso, estamos de acuerdo con Carrasco (2004, 2-3) cuando indica que cada cultura debe ser entendida como "una propuesta global de orden frente al caos, compleja y cambiante, cuyos elementos particulares, sin embargo, pueden parecer arbitrarios desde cualquier otra propuesta global y desde cualquier situación crítica de cambio. Un rasgo fundamental de la condición humana es, pues, la variabilidad y, por ende, la capacidad de adaptación". Por tanto, a partir de las definiciones de la UNESCO, creemos que la mejor simbiosis es pensar (y creer) que todas las corrientes confluyen en la consideración de la cultura como parte del todo social, en absoluto aislada de lo económico, lo político y lo educativo.

Interesante es, en este sentido, la aportación de Bueno (1996), en su obra El mito de la cultura, donde sostiene que este concepto desempeña el papel de idea suprema, de fuerza motora en función de la cual definimos realidades y nos movemos en torno a conceptos como hombre, libertad y nación (el hombre es animal cultural; la verdadera libertad se alcanza a través de la cultura; la nación se define por la cultura, etc.). Así, el Estado ideal para este autor es el Estado cultural, con más rango si cabe que el Estado de derecho y, evidentemente, mucho más importante que el Estado de bienestar. Pero la cultura, según Bueno, sigue sin poder ser definida ya que pocos entienden su concepto y saben explicarlo, hasta el punto de que puede ser considerada como un mito, muchas veces incorporado a los nacionalismos de finales del siglo pasado. Sostiene Bueno que, se observe desde el punto de vista que se observe, la diferencia de cultura se presenta como un hecho mucho más grave que el de las diferencias de clases o las diferencias económicas, afirmación desde luego discutible y con la que no estamos muy de acuerdo. El "peligro" no es cultural, sino económico, como estamos comprobando con la crisis mundial en la que estamos inmersos, pues ya nadie duda de la mercantilización de la vida contemporánea. La economía se impone a los demás sectores sociales, incluidos naturalmente la política y la educación, así que de acuerdo con Bueno afirmamos que cuando se habla hoy de lucha de clases en realidad se está hablando de lucha de culturas.

De todos modos, pensamos que es muy importante para el propósito de este artículo el convencimiento de que la cultura se construye compartiendo significados, que son los que dan sentido a nuestra visión del mundo y nos hacen tener unos u otros comportamientos. Por tanto, la cultura es dinámica, nunca está acabada porque constantemente estamos compartiendo significados como resultado de las nuevas percepciones del mundo que nos rodea. Si la cultura es un constructo en permanente cambio (René, 2006), parece obvio deducir que todos construimos nuestra propia cultura e identidad mediante el encuentro con los demás. Por eso, 
Vidal-Beneyto (2008) habla del concepto de cultura como algo vivo, inmaterial, cotidiano y comunitario, que se produce a partir de las vivencias de los miembros de una comunidad en interacción con su pasado, su patrimonio y su medio natural. La cultura así entendida hace de la afirmación de su diversidad uno de sus principales rasgos y cometidos, lo que la protege frente a la avalancha homogeneizadora de la cultura comercial de masas.

En consecuencia, los seres humanos deberíamos entender la cultura como guía de la experiencia, como vehículo que nos permite ir abriéndonos camino en las diferentes situaciones sociales, al proporcionarnos el sentido y la dirección de éstas. Igualmente, la cultura pone límites a lo que podemos y no podemos hacer, y lo mismo vale para adaptarnos que para transformar los espacios naturales y convertirlos en lugares de convivencia. Todo ello puede conseguirlo el ser humano desde sus referentes axiológicos y culturales. Vivimos y respondemos a la vida culturalmente, pero lo hacemos compartiendo con otros, y ésta es la clave de la cuestión: construimos nuestros espacios físicos y normativos compartiéndolos con los demás.

Teniendo en cuenta lo anterior, creemos que la cultura no debe ser un lugar de enfrentamientos, sino un espacio de intercambio. Es verdad que cada cultura (incluso cada persona) es un mundo diferente, a veces desconocido, pero ello no significa que sea imposible el encuentro entre personas de diversas culturas. Los diferentes puntos de vista que tenemos deben convertirse en una oportunidad para el enriquecimiento cultural, no para la confrontación multicultural ni para alentar posturas próximas al racismo y a la xenofobia. En este sentido, estamos de acuerdo con quienes proclaman que la sociedad debe ser un laboratorio intercultural generador de nuevas culturas y nuevos lenguajes que afirmen y reivindiquen el derecho a ser distintos, y la obligación de buscar espacios comunes de encuentro (Colectivo IOE, 1998).

El problema se produce cuando no sólo se dice que una cultura es diferente a otras, sino que son esas mismas diferencias las que, entre otros condicionamientos socioeconómicos, llevan a la desigualdad, por lo que se piensa entonces que la "única solución" es que las culturas diferentes se integren en la mayoritaria. Es la postura asimilacionista típica del etnocentrismo, que se debe rechazar si se cree en la interculturalidad ya que las políticas asimilacionistas pretenden fagocitar a los diversos grupos culturales y homogeneizarlos en torno a la cultura dominante, lo que ha producido conflictos y problemas de convivencia.

Por todo ello, no extraña que la cultura haya sido puesta en el frontispicio de políticas y estrategias económicas, desde las emanadas del Banco Mundial o la ONU, hasta las propuestas por las regiones o los municipios. Surge entonces la aparente contradicción entre la homogeneización cultural que promueven ciertos discursos sobre la globalización como fenómeno comercial y la realidad de un orden económico y político centrado en la desarticulación de las antiguas pautas de identificación que se basaron en entidades como la nación. En este sentido, nos parece interesante la aportación del sociólogo francés, y director del Centre National de Recherche Scientifique de París, Wolton (2004a), cuando advierte que la 
comunicación en un mundo globalizado no es un problema técnico ni económico, sino que es una cuestión básicamente política (y educativa, añadimos nosotros). Este autor defiende el reconocimiento a la diversidad cultural como factor de paz y está convencido de que creer en una cultura mundial única es muy problemático. La mundialización de la información vuelve el mundo "pequeño", y muy peligroso, sostiene. Nos hace ver Wolton que somos diferentes y debemos aprender (mediante la educación, insistimos) a cohabitar con la diferencia.

A este respecto, cabe indicar que la educación intercultural se constituye en referente básico a desarrollar en los centros a través de su Proyecto Educativo. Proyecto que debe reconocer en sus señas de identidad las características culturales presentes en el contexto y establecer a partir de las mismas los objetivos y las finalidades educativas del centro. De esta manera se evitará la exclusión de los alumnos de culturas diferentes a la mayoritaria y se propiciará la formación en valores y el respeto al que es diferente (Ortega, Mínguez y Gil, 1996), no como algo puntual sino que los valores deben impregnar la vida del centro y todas las áreas del currículum. Algunos de estos valores podrían ser: solidaridad, tolerancia, pluralismo, cooperación, conocimiento de otras culturas, respeto y aprecio a las identidades culturales.

Una propuesta pedagógica que responde a este planteamiento es el Plan de Acogida, que estaría dentro del Plan de Acción tutorial del centro y regulado por las instrucciones sobre compensación educativa y atención al alumnado con integración tardía en centros educativos de la Región de Murcia, y recogido en el Decreto $359 / 2009$, cuya finalidad es dar la bienvenida a los alumnos de diferentes culturas cuando son escolarizados en el centro. Dicho plan permitirá que los alumnos recién incorporados al sistema educativo conozcan las características culturales de su centro y las de sus compañeros. Y ello, evidentemente, sin que se pida a nadie que renuncie a su identidad, pues, como dice Wolton, una cosa es la identidad refugio y otra la identidad relacional: la primera es agresiva y se cierra en sí misma cuando alguien se siente amenazado como autodefensa ante otras identidades; en cambio, la segunda busca la cooperación. En el epígrafe siguiente profundizaremos en torno a estas cuestiones sobre la identidad.

\section{LA IDENTIDAD}

Todo individuo es pluricultural, porque las culturas, ya lo hemos visto, no son islas monolíticas, sino que están configuradas por diversas aportaciones de otras culturas con las que se relacionan. La identidad individual procede del encuentro de múltiples identidades colectivas en una sola persona, y cada una de nuestras numerosas pertenencias contribuye a la formación del ser único que somos (Todorov, 2008). No obstante, y a juicio de este autor, para los miembros de la comunidad que forman parte de una cultura, ésta es una identidad estable y diferenciada que ofrece a cada individuo el fundamento de su identidad colectiva; por eso creen que todo cambio que afecte a su cultura es un atentado contra la 
propia identidad. Y en el momento actual, en el que las identidades colectivas se trasforman cada vez más deprisa por efecto de los intercambios resultantes de la globalización y la inmigración, los grupos culturales se vuelven más defensivos y reivindican de una manera más fuerte su identidad originaria.

En ese proceso de afirmación de la identidad es evidente que las personas necesitan detectar semejanzas y diferencias entre las diversas culturas y, en función de este juego de similitudes y diferencias, establecen categorías que les pueden servir para identificar y clasificar. Pero ese proceso de diferenciación implica generalmente una simplificación (por ejemplo, cuando se clasifica en función del tipo de vestimenta), porque normalmente se consideran ciertos rasgos o características, normalmente externos, y se ignoran otros que podrían ser no menos importantes. Así, se debe tener en cuenta que tanto las categorías que se utilizan para clasificar como los valores añadidos a ellas son constructos elaborados por las propias personas; es decir, no son en absoluto atributos objetivos, sino que son construidos social y personalmente. Por tanto, las categorías con las que clasificamos no son neutras (Téllez, Málik, Mata y Sutil, 2005), sino que están influidas por nuestras percepciones, experiencias y valores.

Considerando lo expuesto anteriormente, entenderemos mejor la idea central de Wolton expuesta en su obra La otra mundialización (2004b): el universalismo no debe ser entendido como unificación cultural, cuya imposición sólo conduce al conflicto de identidades, sino como aceptación común de la diversidad cultural, lo que significa la convivencia entre culturas e identidades diferentes. En consecuencia, según Wolton, el universalismo no debe consistir en la unificación de todas las identidades, tras ser asimiladas las culturas minoritarias por el predominio de la cultura occidental, según el famoso melting pot anglosajón, que integra a los afines y excluye a los diferentes, sino que exige el reconocimiento de la diversidad del otro.

Así que debemos reconocer que todos somos depositarios de dos herencias: una, vertical, que nos viene de nuestros antepasados, de las tradiciones de nuestro pueblo; la otra, horizontal, que es producto de nuestra época, de nuestros contemporáneos, y es desde luego la más determinante, aunque generalmente nos aliamos con la vertical (Maalouf, 2008). Dice Sami Nair (2006), a este respecto, que el siglo XXI será el siglo de las identidades porque la mundialización está provocando el contacto cada vez mayor entre poblaciones, y la reacción de éstas frente al contacto es, cada vez más, la radicalización de las identidades en sus propios fundamentos. No por casualidad, dice, la religión se está radicalizando y cobrando cada vez mayor protagonismo como reducto de defensa de las creencias, pero también de la propia identidad, pudiendo llegar a convertirse en un factor determinante en los procesos de exclusión-inclusión.

No deberíamos olvidar, como expresamos anteriormente, que los procesos de globalización y mundialización permiten interpretar las diferentes culturas como realidades abiertas, donde se puede rastrear la huella de una humanidad común. Ninguna cultura es tan hermética ni tan singular que no esté influida por otras 
culturas; y, a su vez, toda cultura puede ejercer algún tipo de influencia sobre otras (Pérez de Cuéllar et al., 1997). Por eso, sostiene Umberto Eco (1998) que el hombre del siglo xxi será cada vez más un hombre mestizo, rico en identidades y de pertenencias múltiples. En el "supermercado" mundial de la cultura escogerá artículos diversos según sus preferencias, sus valores y sus creencias. Y lo escogerá no para siempre y de una vez, sino paulatina y provisionalmente, haciendo constantes reajustes culturales. Por tanto, es importante resaltar que la identidad cultural de los grupos debe contemplarse como una serie de procesos sociales complejos que se articulan a partir de la interacción entre las personas (Marí, 1999). Ello quiere decir que toda sociedad está permanentemente atravesada por múltiples referentes culturales que nos impiden considerar el sentido de la identidad cultural o grupal como un rasgo definido y estable en relación a un colectivo determinado. En una sociedad postmoderna se precisa el desarrollo de una identidad flexible y versátil, como indica Bernal (2011), que sea capaz de afrontar los cambios a los que una persona tiene que enfrentarse a lo largo de su vida.

Al mismo tiempo, hemos de tener en cuenta que el espectacular avance de las tecnologías de la información ha hecho que se supriman ciertas fronteras, poniendo en contacto a personas de cualquier parte del mundo en unos segundos. Esto hace que se formen nuevas agrupaciones de personas en torno a intereses comunes a expensas de los territorios. Es lo que se ha llamado identidad moral (Marín, 2005), una nueva identidad cultural basada en el mestizaje de los intercambios en los ámbitos científicos, tecnológicos y artísticos. Esta identidad, que podríamos catalogar como postmoderna, conformada por una cultura mediática, es diametralmente opuesta a la surgida de la modernidad europea, basada en la tradición y la historia y próxima a los nacionalismos. Aunque el comunicólogo francés Dominique Wolton (2004b), al que nos hemos referido anteriormente, insiste en que en tiempos de mundialización y de protesta contra las pérdidas de identidad se debe desmitificar el poder de las nuevas tecnologías de la comunicación, sobre todo cuando se dice que la globalización, apoyada en las tecnologías de la información, está barriendo las tradicionales culturas para fundirlas en una sola matriz universal (recordemos la profecía de Mc Luham y su aldea global). Sin embargo, las revueltas iniciadas en 2011 en los países árabes, apoyadas en las redes sociales, quizá hagan repensar a Wolton sus afirmaciones.

Conocido es, igualmente, que la identidad cultural se refiere al grado en que una persona se siente parte de un grupo cultural, del propio grupo de referencia en el que ha crecido (Jiménez y Aguado, 2002; Aguado, 2003). Así, incluye una compleja combinación de factores tales como autoidentificación, sentido de pertenencia o exclusión y deseo de participar en actividades de grupo. Del mismo modo, la identidad cultural hace referencia a la socialización sociopolítica y económica y a la socialización en creencias y valores.

Hablamos, pues, de identidad como nexo interdisciplinar y como puente entre la cultura familiar y la cultura social (Vila, Esteban y Oller, 2010), pero también como conflicto entre esos espacios de relación. La identidad es un sentimiento 
que se construye y se diferencia por medio de una serie de identificaciones que se realizan a través de una socialización primaria que requiere para su construcción un marco cultural concreto. Y es en este proceso donde puede surgir el conflicto, porque si lo primero que interiorizamos es una cultura, esa cultura, en cuanto definición-delimitación, nos puede cerrar a las demás culturas. Sin embargo, también podemos aprender y socializarnos en una cultura de apertura a partir de un intercambio enriquecedor con los otros, lo que abre una gran esperanza y es de tremenda trascendencia puesto que denota que las identidades se construyen en un proceso de contraste dialógico con los otros.

Por ello, la identidad cultural debe ser marcada dentro de una constelación de identidades particulares (Marín, 2005), y no ser entendida como refugio autista etnocéntrico, sino como apertura a la alteridad de las otras identidades ajenas. Para ello, es ineludible una política democrática que, frente al melting pot, reconozca los derechos políticos y sociales, pero también culturales de las identidades singulares (Wolton, 2004b). Esa política democrática debe considerar seriamente que tanto los Estados-nación como los partidos y movimientos políticos basados en las clases sociales se han visto debilitados, y las personas buscan grupos a los que pertenecer con seguridad en un mundo en el que todo se mueve a un ritmo vertiginoso. Y esa seguridad parecen encontrarla en los llamados grupos de identidad (Hobsbawm, 2000). El problema es que, normalmente, las identidades colectivas se definen negativamente, en contraposición a otras identidades colectivas: "Nosotros no somos ellos, somos diferentes a ellos"; y este sentimiento es más fuerte que las características comunes que pudiera contener el colectivo "Nosotros". Por eso, estamos de acuerdo con Maalouf (2008), quien afirma que, cuando concebimos nuestra identidad como integrada por múltiples pertenencias: historia, religión, costumbres..., desde el momento en que nos sentimos parte de mestizajes diversos, dejamos de hablar de "nosotros" y de "ellos" como si hablásemos de dos grupos diferentes y dispuestos a enfrentarse. Simplemente comenzamos a tener una relación mucho más cercana con todos, y no sólo con "los de mi tribu".

"No tengo varias identidades, tengo solamente una", dice igualmente este autor (2008, 10); una identidad que es producto de todos los elementos que la han configurado mediante una "dosificación" singular que nunca es la misma en dos personas. Estamos de acuerdo con Maalouf cuando afirma que, prácticamente, en todas las personas coinciden pertenencias múltiples que a veces se oponen entre ellas y les obligan a elegir, con el consiguiente desgarro. Pero la jerarquía que podamos establecer entre los elementos que configuran la identidad no es inmutable, sino que cambia con los años y con las experiencias y circunstancias vitales, como vimos anteriormente al analizar la cultura. Según Bernal (2003, 131), "la construcción de la identidad personal es un proceso eminentemente dinámico, puesto que en el curso de la vida misma los elementos configuradores de la identidad pueden modificarse". La personalidad, como parte de la identidad personal, puede cambiar, en tanto proceso holístico, como aquello que somos, pero también como aquello que podemos llegar a ser (Bernal, 2005). Sin embargo, en el mundo actual, los 
que reivindican una identidad compleja se ven discriminados y marginados, entre otras cosas, porque nada hay en las leyes de los países receptores de inmigración que permita asumir en armonía una identidad compuesta y compleja. Es en este sentido que Maalouf (2008) llama identidades asesinas a las actitudes y posturas que reducen la identidad a una pertenencia sectaria, intolerable, dominadora y, a veces, suicida.

A este respecto escribe Sen (2007) que muchas identidades, que coinciden en una persona o en un grupo, suelen ser complementarias y no discriminatorias entre sí. Su reconocimiento da sentido a la democracia, al ejercicio de la libertad y al pluralismo de las sociedades modernas. Uno puede ser a la vez español, europeo, sentirse murciano, vasco o catalán, católico, judío o musulmán, sentir su identidad en todo ello a la vez, incluso de manera prioritaria en alguna de ellas, según las ocasiones, pero una identidad no anula a las otras ni tiene que ser contradictoria con ellas. Por esto, nunca debe ser considerada como una amenaza la identidad de otros frente a lo que consideramos nuestra identidad, porque, en tanto que construcción inacabada, elaboramos otras nuevas a partir de las diversas identidades presentes en un espacio concreto de convivencia. Por esa razón, la identidad personal no puede formarse sin el reconocimiento explícito de la existencia de la diferencia (Galino y Escribano, 1990).

Llegados a este punto, cabría plantearse la siguiente pregunta: ¿cómo podríamos conseguir que en la realidad pluricultural se puedan llegar a mantener las identidades propias de cada cultura y, al mismo tiempo, obtener un enriquecimiento mutuo? La clave, desde nuestro punto de vista, está en la educación. No sólo en la educación, evidentemente, pero tenemos la gran esperanza de que, a través de ella, se puedan mostrar, entender y conciliar las distintas culturas que integran una sociedad. La educación continúa siendo una gran oportunidad para poder optimizar la riqueza cultural de la mezcla de pueblos. Pero no olvidemos nunca que, en último término, la cuestión de la inmigración es ante todo una cuestión de derechos y deberes que de ningún modo prejuzga el devenir de la identidad de la sociedad. Las personas de otras culturas deben poder elegir entre integrarse plenamente o seguir conservando su identidad, siempre que ésta respete los derechos y deberes del país de acogida, o, como decía Maalouf (2008), construir una identidad resultante de sus diferentes influencias vitales. Y la educación también deberá tener en cuenta estas opciones a la hora de plantear sus alternativas.

En efecto, la universalidad cultural que reclamamos implica que todos los ciudadanos disfruten de idénticos derechos y deberes, siendo el sistema educativo un gran medio para lograrlo, puesto que, conforme al modelo ilustrado, permite a los sujetos convertirse en "mayores de edad", esto es, en personas informadas y formadas capaces de tomar decisiones por sí mismos, liberándose de la ignorancia y de los prejuicios. Tal es así que sin educación la democracia se convierte en pura demagogia, y sin democracia cultural la educación se transforma en mera instrucción técnica y en adoctrinamiento. Y si la educación, como dice Bernal (2003, 131), no sólo pretende configurar la identidad personal en un proceso claramente 
humanizador, sino eminentemente emancipador, ello sólo es posible cuando el sujeto se implica directamente en este proceso de construcción de su personalidad moral "a través de sus múltiples interacciones con otros individuos en entornos cada vez más complejos y plurales".

De lo anterior se desprende que la identidad cultural implica aprendizaje de normas, valores, costumbres, etc., en un proceso complejo y globalizado en el que el encuentro con los otros es fundamental para conseguirlo. De ahí que formar la identidad implique ir hacia el encuentro de los demás; significa no el aislamiento sino la capacidad de intercambio entre grupos y culturas (Aguado, 1996). Es más, a juicio de esta autora, sólo cuando los miembros de un grupo cultural se sienten seguros en su propia identidad, se sienten abiertos y generosos respecto a otras culturas; por el contrario, las culturas cerradas tienden a debilitarse e incluso a desaparecer. Así, la identidad debe suponer tanto la valoración de la cultura propia como la apertura a otras culturas. El problema se plantea, como se expresó anteriormente, cuando esta identidad es excluyente, porque entonces aparecen la xenofobia y el racismo, el rechazo hacia cualesquiera otras culturas y grupos, rechazo que puede llevar a la hostilidad y a la violencia.

El proceso de construcción de la identidad es un proceso educativo, pero también social, no es sólo una labor docente para transmitir en la escuela, aunque evidentemente el trabajo de ésta es fundamental e imprescindible. Si no hay una comunión adecuada entre lo escolar y lo extraescolar difícilmente podemos construir la identidad (Essomba, 2005). Por ello cobra suma importancia la dimensión comunitaria en el proceso de construcción de la identidad. ¿Cómo puede ayudar la educación a ello? La educación debería trabajar en pro de un currículum intercultural que organizase conceptos y contenidos alrededor de las contribuciones, perspectivas y experiencias; y confrontase temas sociales que incluyesen la etnia, la clase socioeconómica, el sexo y la xenofobia, entre otros.

Se trataría de evitar posturas de asimilación o de integración de una subcultura a una cultura dominante a la hora de diseñar el currículum, lo que haría peder las diferentes identidades culturales, y de adoptar planteamientos donde las diversas culturas tengan un tratamiento de igualdad con relación a las prácticas y a los valores que las sustentan: "El problema del currículum multicultural no es algo que afecte o se refiera a gitanos o minorías culturales, raciales o religiosas, con vistas a que tengan oportunidad de verse reflejadas en la escolarización como objetos de referencia y de estudio, sino que es un problema que afecta a la "representatividad" cultural del currículo común que durante la escolaridad obligatoria reciben los ciudadanos" (Gimeno, 1992, 128). Así, el planteamiento de un currículum multicultural debe llevarse a cabo desde un marco democrático de toma de decisiones sobre los contenidos de la enseñanza en el que participen profesores, padres, alumnos, Administración, entidades locales, etc., con una mentalidad abierta y democrática.

Todos los temas curriculares que se desarrollen no necesariamente tienen que ser vistos desde puntos de vista culturalmente distintos sino que se deben elegir 
aquellos que mejor se presten a ello según el tema a tratar, el área a que pertenecen, las características del alumnado y el pensamiento crítico que se pretende generar. Lo verdaderamente interesante es que estas actividades se incluyan y traten como manifestaciones culturales de la vida real de esos grupos y se vinculen a los contenidos curriculares que cada día se tratan en las distintas áreas (Banks, 1989). Se desarrollarían así contextos interculturales con un gran potencial en sí mismos como constructores de espacios inclusivos aptos para el aprendizaje y respeto de la identidad de todo el alumnado. La Guía de autoevaluación de contextos interculturales para Educación Secundaria (Arnaiz et al., 2006) puede constituirse en un instrumento que ayude a los centros a realizar el diagnóstico de su grado de desarrollo a este respecto, propiciando procesos de autoevaluación y mejora. En definitiva, abordar la identidad cultural desde este planteamiento educativo podría servir de ayuda a los centros que quieren trabajar desde una perspectiva intercultural.

\section{EL RACISMO}

Una vez desarrollados los epígrafes referidos a la cultura y a la identidad, nos referiremos ahora al racismo, una lacra social permanentemente presente, en sus variadas manifestaciones, en la historia de la humanidad, y que ha llegado a tomar derroteros preocupantes en nuestro país. Especialmente, en algunos espacios y situaciones concretos aparecen actitudes hacia los inmigrantes que nos invitan a estar alerta ante posibles brotes racistas en todas partes.

Todos somos conscientes de que la vida de las personas que deben emigrar no es en absoluto fácil. No lo es, ciertamente, la partida, el viaje, ni aprender lenguas y modos culturales diferentes al llegar a un nuevo espacio, lo que genera inquietud, esa típica inquietud de todo inmigrante al llegar a un país extraño (Vieviorka, 2009). Pero también sabemos que es todavía más duro, a veces mortal, para los clandestinos, siempre expuestos al abandono y a la represión. La inserción en las nuevas sociedades tampoco es fácil; en el terreno económico la explotación es lo que prevalece, sin coberturas sociales y con salarios aleatorios; socialmente su alojamiento y asentamiento se realiza en las zonas más marginales, lo que conlleva una mayor facilidad de control, que a veces se convierte en guetización (García, 2004); y políticamente la regla es habitualmente la ausencia de derechos cívicos. Por tanto, nos encontramos ante un tema fundamental de derechos humanos (Silva, 2008).

Interesante nos parece, a este respecto, una publicación del Colectivo IOE (2009) que hace referencia a la condición inmigrante en España, basada en una investigación cualitativa (2008) que ese propio colectivo desarrolló, en la que destacaban cuatro posiciones básicas que podemos encontrar en los colectivos de inmigrantes en su proceso de integración en España: inserción subalterna (agradecimiento por la acogida, asimilación a la cultura mayoritaria y empleo como mano de obra), integración igualitaria (igualdad formal, respeto a la diversidad cultural y actitud competitiva de los trabajadores inmigrantes), repliegue defensivo (reclusión 
sobre la propia cultura frente al intento de asimilación de la cultura mayoritaria, segregación y "nichos laborales" con trabajos específicos para la propia comunidad) y proyección instituyente (reconocimiento de las ventajas de la relación intercultural, diversidad entendida como enriquecimiento cultural para todos, ciudadanía participativa e inserción laboral crítica).

Por otra parte, cuando la sociedad de acogida dice que aceptará los flujos de inmigrantes "atendiendo a las necesidades del mercado", cuando se quiere adaptar los flujos migratorios a las demandas laborales, estamos apelando a la ideología de la exclusión, de la discriminación de la población inmigrante en términos sociales, políticos y, en definitiva, en términos de derechos humanos, como hemos dicho anteriormente. A juicio de Legrain (2008, 115), las propuestas políticas europeas de "selección" de la inmigración y de "migraciones seleccionadas" no son sino "el reflejo de esta consideración de las migraciones, adaptadas exclusivamente a los intereses de la globalización y de quienes la dirigen".

Pero los inmigrantes, portadores de la diversidad, no son sólo los protagonistas de un fenómeno estructural, sino que también son personas concretas, de carne y hueso, que bajo ningún concepto pueden ser tratadas como criminales, aunque alguno de entre ellos, al igual que ocurre entre los autóctonos, cometa algún delito. Por eso, culpabilizar a los inmigrantes de nuestros males no es sino negarse a ver lo complejo de las nuevas realidades, en especial que ellos son nuestros conciudadanos y que aportan mucho más de lo que reciben (Cachón, 2008). Esto es muy importante que se tenga en cuenta, porque demasiadas veces la sociedad que los recibe muestra aspectos contradictorios y en general poco beneficiosos para muchos inmigrantes: rechazo cultural y religioso, etiqueta de peligrosos, etc. De ahí a las actitudes y comportamientos racistas y xenófobos (a menudo disfrazados bajo el manto de la "seguridad"), el trecho se recorre fácilmente, como lo muestran en nuestro país algunos episodios vergonzantes, como los acaecidos en El Ejido (Almería) hace unos años, o los más recientes ocurridos en Salt (Girona), donde los brotes racistas llegaron a la violencia física. No es extraño, por todo ello, que el miedo, el desequilibrio y la intranquilidad se conviertan en una constante de la vida de los inmigrantes que llegan a España. Conflictos que se han dado también en todas partes de Europa occidental, fundamentalmente en Francia e Italia.

El miedo a los inmigrantes, generado interesadamente por algunos sectores sociopolíticos, unido a la tradicional existencia de núcleos de xenofobia y racismo, a veces incluso institucional, acaban imposibilitando las condiciones que permitirían la tan cacareada integración (Zamora, 2006). Verdaderamente, la inmigración es una cuestión compleja y difícil, pero para nosotros no es el problema, ni siquiera un problema. Más bien, representa la solución a muchos de los problemas de nuestras "civilizadas" sociedades que envejecen a pasos agigantados. Y, precisamente, para que la inmigración sea vista más como solución que como problema, algunos autores (Dusi, 2009; Arnaiz, 2011) siguen viendo la alternativa pedagógica como la más acertada para hacer frente a estas situaciones problemáticas. Por ello, la educación (intercultural), en el marco de sociedades libres, abiertas y plurales, intenta 
contribuir a la construcción de ciudadanos iguales, pero diferentes, en la medida de sus posibilidades, considerando las aportaciones de Naïr (2010) cuando afirma que la clave de la convivencia intercultural es política más que de otra índole. Por este motivo, considera que la inmigración debe estar en el centro de las políticas públicas y no en la periferia, como ocurre cuando es entendida como un instrumento para atender las necesidades de las personas de otras culturas que llegan a un país buscando mejores expectativas vitales.

En todo caso, el término racismo es relativamente reciente (la primera acepción del diccionario Larousse es de 1932), aunque la discriminación y las actitudes de rechazo del otro son mucho más antiguas, probablemente se remonten a las primitivas formas de organización humana. En general, se trata de sobrevalorar las características de una cultura que comparamos con otra, al tiempo que infravaloramos esta última. Recientemente se identifica el racismo con el etnocentrismo, pero a juicio de Genovese (2003) es una postura exagerada. El colonialismo y los intentos imperialistas del siglo XIX sirvieron, en buena medida, para envenenar las relaciones entre culturas con los tintes racistas que impregnaron esas relaciones. Un siglo antes, en el XVIII, políticos e intelectuales europeos como Linneo, Leclerc o Buffon mostraron su convencimiento de que los seres humanos se dividían en "razas", por lo que el término "raza" adquirió un carácter antropológico decisivo, ya que a éstas se les asignaban unas características inmutables heredadas genéticamente que determinaban no sólo los rasgos físicos, sino también los intelectuales y actitudinales. De ahí se pasó a considerar a unas "razas" superiores a otras.

Así que tradicionalmente se ha dado un racismo biológico, definido como un determinismo que atribuye al patrimonio genético de un grupo características intelectuales y morales, al tiempo que establece una valoración discriminatoria entre unos grupos y otros. Según esto, habría "razas" humanas que presentarían ciertas diferencias biológicas que podrían justificar el dominio sobre otras "razas". Sin embargo, ahora podemos afirmar que lo que normalmente se entiende como "raza" es simplemente un estereotipo cultural basado en la apariencia externa y el prejuicio. Científicos mundiales de reconocido prestigio (Cavalli-Sforza, Menozi y Piazza, 1995) publicaron trabajos sobre el ADN en los que niegan toda base científica sobre el racismo. Los avances en el campo de la genética nos han hecho ver que no existe base científica para hablar de diferentes razas en la especie humana. La diversidad de ésta se basa en la combinación al azar de más de 20.000 genes. El color de la piel o la forma de los ojos nada nos dicen de la forma de ser de una persona, ni de sus creencias, actitudes, ni capacidades. Y Gould (2007), divulgador científico desgraciadamente fallecido, desmontó las teorías que políticos interesados (para legitimar su poder) y científicos aún más interesados han construido a lo largo de la historia sobre la supuesta superioridad de una "raza" sobre otra y de los hombres sobre las mujeres. Gould denunció las falsedades científicas en un magnífico libro: La falsa medida del hombre. Aun así, el racismo sigue vigente y se manifiesta muchas veces de forma cruel y violenta, pero otras lo hace de forma sutil y sibilina. Ni siquiera 
el exhaustivo conocimiento científico (que niega su existencia) ha conseguido que esta categoría de "raza" desaparezca del imaginario colectivo.

Eso, en cuanto al llamado racismo biológico, pero en la actualidad nos encontramos con otro tipo de racismo, el denominado racismo cultural o simbólico. No se admite la superioridad de una "raza" sobre otra, pero sí de una cultura sobre las demás. De este modo, la poca recomendable categoría de "raza" es sustituida por la más aceptable de cultura, y la clasificación discriminatoria de base biológica se transforma en cultural o simbólica. Tenemos, como ejemplo, el conocido libro, del autor recientemente fallecido Huntington (1996), sobre el choque de culturas, que tiene su origen en un artículo del mismo título publicado anteriormente y que tuvo una gran impacto mediático. Su repercusión, entre otras razones, debe ser atribuida a la propuesta de una explicación simple y accesible sobre la complejidad del mundo internacional y la manera de evitar los conflictos futuros. Huntington indica en su libro que el bienestar de Occidente está amenazado por la llegada de millones de personas de otras culturas; tras la caída del muro de Berlín. Las fuerzas de oposición ya no serían Estados Unidos y la Unión Soviética, sino que el enfrentamiento vendría dado por diferentes estilos culturales entre grupos de países que pertenecen a una u otra civilización. Concretamente, Huntington afirma que los conflictos mundiales tendrán su origen en las diferencias religiosas, por ser éstas las que más identifican a una cultura.

Estas actitudes ya las adelantó Barker (1984), cuando nos mostró el paso del racismo sustentado en la inferioridad biológica al racismo basado en las diferencias culturales como criterio de legitimación del mismo. La cultura dominante es inmodificable, homogénea, monocultural e impenetrable, por lo que se niegan los valores de las demás culturas "de acogida". Así, junto a la discriminación abierta, la creciente diversidad de las poblaciones está descubriéndonos también otras formas de racismo más sutiles, pero igualmente perniciosas (San Román, 2008).

Por tanto, desde sus orígenes, el rol del racismo ha consistido en la negación de la capacidad de los humanos pertenecientes a ciertos grupos, calificados como "razas", para acceder a la toma de decisiones en materia social, política y económica y, valiéndose de esa atribución, legitimar su explotación en todas las facetas de la vida privada y pública. El poder así ejercido se plasma fundamentalmente de tres maneras diferentes (García, 2004):

a) Epistemológicamente: quien nombra, clasifica, define y evalúa a otros se atribuye el poder del conocimiento.

b) Sociopolíticamente: sólo si los racistas tienen el poder (material y/o simbólico) y la ocasión para actuar y someter a otros pueden obrar de acuerdo con su lógica.

c) Simbólicamente: el ejercicio del racismo divide, sin solución de continuidad, a los grupos humanos y sociales, asignándolos inexorablemente a su diferencia y a su inferioridad. En este contexto, las actuales minorías socioculturales serían representativas de la parte que pierde en esa 
división, frente a quienes detenta el poder, vinculado normalmente al control del aparato del Estado.

En todo caso, nos interesa resaltar que tanto el racismo biológico como el cultural tienen consecuencias en el ámbito educativo. El racismo biológico, en efecto, justifica una jerarquía natural, una subordinación de unas etnias a otras. Igual debía ocurrir en la sociedad, que debía darse una jerarquía. La educación tendría el papel de formar según las "aptitudes naturales". Por su parte, el racismo cultural, basado en las diferencias, justifica la separación por grupos culturales en las aulas.

Nosotros estamos convencidos de que, para combatir prejuicios como el del racismo, la educación debe implicarse conscientemente, sin presuponer que el conocimiento es, per se, un antídoto suficiente, aunque siga siendo necesario. En efecto, sabemos que los prejuicios son una forma de pensamiento presente en todos nosotros, que es frecuentemente utilizada, y que no se basa en hechos objetivos, sino en las conclusiones elaboradas a partir de la experiencia directa y en las generalizaciones que hacemos sobre valoraciones de naturaleza emotiva. Naturalmente, hay prejuicios positivos: por ejemplo, la sobrevaloración de la cultura europea o si creemos que todos los gitanos son buenos bailando flamenco; y prejuicios negativos: si pensamos que las culturas no europeas son inferiores o si creemos que todos los gitanos son ladrones. En todo caso, lo que nos interesa aquí es el hecho de que los prejuicios crean tensiones y daños sociales, discriminaciones, desencuentros que pueden dar lugar a comportamientos violentos, porque generalmente, el prejuicio es un juicio negativo sobre el otro, construido a priori, un juicio que atribuye elementos negativos a los otros, conduciendo a pensar mal de los diferentes a nosotros sin razón objetiva alguna, es decir, sin motivo real (Genovesse, 2003).

Por todo ello, algunos autores (Portera, Dusi y Guidetti, 2010) han enfatizado la importancia y la urgencia de considerar la educación intercultural como educación para la ciudadanía, educación para la inclusión y para la convivencia. Y no faltan en nuestro país propuestas concretas aplicables al ámbito escolar (Besalú y Tort, 2009; Escarbajal Frutos, 2009). Entre ellas cabe destacar a nivel estatal los Programas de Cooperación Territorial, ofertados por el Ministerio de Educación, entre los que se encuentra el "Programa de mejora del éxito escolar y la participación educativa" (Orden 26 de julio de 2011), con el objetivo, entre otros, de mejorar el éxito escolar de los alumnos para fijar objetivos propios y adoptar medidas, acordadas con la Consejería de Educación, Formación y Empleo en relación, entre otros, con la organización del centro, la gestión de los recursos, el desarrollo de los procesos de enseñanza y aprendizaje, la acogida e inserción socioeducativa del alumnado, la participación de las familias en el proceso educativo de sus hijos, así como la coordinación y colaboración con otras instituciones y entidades públicas.

Otras de las actuaciones que se pueden realizar en los centros es un Plan de Convivencia (Orden 20 febrero de 2006) que, con la colaboración de la jefatura de estudios para su elaboración y desarrollo, pondrán en marcha las medidas adoptadas para la mejora de la convivencia escolar, la prevención de conflictos, y evitar 
brotes de racismo desde dinámicas de conocimiento del otro, tanto en el propio centro como en el entorno más inmediato el mismo.

\section{A MODO DE CONCLUSIÓN}

A pesar del llamado "síndrome de la fortaleza asediada" (Binanti, 2010), que parece estar padeciendo la vieja Europa ante la inmigración, ésta, y la consiguiente relación entre culturas, ha hecho percibir a las sociedades receptoras que el "nosotros" no es una categoría inmutable: tan "extraños" son los que vienen de fuera como los habitantes del país receptor, incluso internamente, porque la situación de pluriculturalidad se debe tanto a las minorías procedentes de los fenómenos migratorios como a situaciones internas en las que los diferentes grupos culturales que viven en un mismo espacio reivindican sus señas de identidad.

En la Grecia clásica se distinguía entre "nosotros" y los "bárbaros", los otros, los extranjeros. La frontera entre ambos era el conocimiento de la lengua griega; pero más tarde la etiqueta de "bárbaros" pasó a denominar también a los "no civilizados" o "salvajes". Mucho han cambiado las cosas desde entonces, pero la frontera, unas veces simbólica, otras ideológica, afectiva o emocional, todavía persiste entre los inmigrantes y las sociedades que los reciben. ¿Quién es hoy «bárbaro”? De acuerdo con Todorov (2008), el bárbaro es todo aquel que niega la plena humanidad de los demás. Otra forma diferente de barbarie es la discriminación institucional hacia todos aquellos que no pertenecen a nuestra comunidad cultural. Lo mismo se podría decir del término "civilizado": es civilizado, en todo momento y en todo lugar, el que sabe reconocer plenamente la humanidad de los otros.

La complejidad es algo consustancial a la persona y a la sociedad, no es algo negativo. De la misma manera, las culturas son fenómenos pluriformes que se producen como procesos continuados de creación y recreación colectiva (Casanova, 2005). En consecuencia, no es muy exacto hablar de cultura universal, ni siquiera de cultura occidental, sino de culturas particulares y de culturas híbridas; tampoco se debe establecer ningún tipo de jerarquía entre culturas. Pero esto no significa que debamos apostar por el relativismo cultural, al considerar que cada cultura tiene sus peculiaridades que deben ser respetadas porque, de ese modo, las posiciones relativistas harían muy difícil la interrelación entre culturas, la interculturalidad.

En este sentido, estamos convencidos de que convivir y trabajar de manera conjunta, al tiempo que mantenemos nuestras identidades y diferencias culturales, es la clave de una sociedad intercultural, y es la base para la construcción de la democracia. Esta opción puede estar en peligro si mostramos obsesión por la propia identidad frente a las otras (postura propia, especialmente, aunque no sólo, de los nacionalismos), por la globalización cultural, con los intentos de homogeneización, y por los integrismos tendentes a las limpiezas étnicas. De ahí que periódicamente la ONU $(2001,2009)$ haga llamadas frente al racismo y la xenofobia. La gravedad de la situación ha impulsado a este organismo internacional a cele- 
brar sucesivos encuentros y foros (Durban, 2001; Ginebra, 2009). Sin embargo, podríamos preguntarnos si estas iniciativas han pasado a ser sólo testimoniales porque hoy el racismo, la hostilidad y la violencia hacia los otros han invadido el planeta y millones de personas carecen de los más elementales derechos civiles, sociales y políticos o sencilla, dramática e impunemente son eliminados. Y es que el racismo hunde sus raíces en la xenofobia, en el miedo al extraño, que se da tanto en el humano como en los animales, en la desconfianza hacia "lo que viene de fuera".

Por todo ello, como educadores necesitamos conocer la trama oculta de prejuicios racistas y xenófobos existentes en cada cultura antes de proponer cualquier intervención sociocultural, y ello teniendo en cuenta además que la educación sigue siendo el recurso privilegiado para fomentar el respeto a otros pueblos y culturas. No obstante, insistimos en lo que hemos señalado reiteradamente en este artículo: las leyes deben tratar a todos los ciudadanos por igual, sin distinción de culturas. En una sociedad global, multiétnica y multicultural, es inconcebible un concepto de ciudadanía que no sea inclusivo (Arnaiz y De Haro, 2004; Portera, Dusi y Guidetti, 2010). Así pues, el futuro no se puede visualizar sin la perspectiva pluricultural, y ésta es impensable sin la educación para la ciudadanía (Santerini, 2009).

\section{REFERENCIAS BIBLIOGRÁFICAS}

Abdallah-Pretceille, M. (2006) Tra etiche e pragmatismi nell'educazione interculturale, en POrTERA, A. (a cura di) Educazione interculturale nel contesto internazionale. Milano, Angelo Guerini.

Aguado, T. (1996) Educación multicultural. Su teoría y su práctica. Madrid, UNED.

- (2003) Pedagogía intercultural. Madrid, McGraw-Hill.

ARNÁIZ SÁNCHEZ, P. (2011) Luchando contra la exclusión: buenas prácticas y éxito escolar. Innovación Educativa, 21, 23-35.

ARnáIz SÁNCHEZ, P. et al. (2006) Guía de autoevaluación de contextos interculturales. Murcia, Consejería de Educación y Cultura. Disponible en: Formato CD para Windows. También en http://guia.murciadiversidad.org/ para los Centros Educativos de la Región de Murcia [consultado 31-05-2011].

ARnáiz SÁnchez, P. y De Haro Rodríguez, R. (2004) Ciudadanía e interculturalidad: claves para la educación del siglo XXI. Revista Educatio Siglo XXI, 22, 19-37.

BANKS, J. A. (1989) Multicultural Education: Characteristic and goals, en BANKs, J. A. y McGeE, Ch. A. (eds.) Multicultural Education: Issues and Perspectives. Boston, Allyn and Bacon, $2-26$.

BARKER, M. (1984) The New Racism: Conservatives and the ideology of the Tribe. Frederick, Aletheia Press.

BARTOlomé, M. (2004) Educación intercultural y ciudadanía. Consultado el 10 de mayo de 2011. http://www. aulaintercultural.org.

Bernal Guerrero, A. (2003) La construcción de la identidad personal como proyecto de educación moral. Supuestos teóricos y delimitación de competencias. Teoría de la Educación. Revista Interuniversitaria, 15, 129-160. 
- (2005) Reconceptualización de la identidad personal y educación para la autodeterminación posible. Teoría de la Educación. Revista Interuniversitaria, 17, 97-128.

- (2011) Postmodernización y educación. Notas para el debate de una narrativa pedagógica centrada en la identidad. Educación XXI, 14 (2), 285-302.

BESAlÚ, X. y TORT, J. (2009) Escuela y sociedad multicultural. Sevilla, MAD.

Beuchot, M. (2004) La filosofía ante el pluralismo cultural. Consultado el 15 de abril de 2011. http://www.oea.ajusco.upn.mx/beuchot.htm.

Binanti, L. (2010) La sindrome alla fortezza assediata, en A. PORTERA, A.; Dusi, P. y GuidetTi, B. (a cura di) L'educazione interculturale alla cittadinanza. Roma, Carocci, 147-152.

Bueno, G. (1996) El mito de la cultura. Ensayo de una filosofía materialista de la cultura. Barcelona, Prensa Ibérica.

CACHÓN, L. (2008) La integración de los inmigrantes en España: debates teóricos, políticos y diversidad territorial. Politica y Sociedad, 45, 205-235.

CAMBI, F. (2010) Cittadinanza e globalizzazione. Una sfida educativa e pedagogica, en PoRTERA, A.; Dusi, P. y GuideTTI, B. (a cura di) L'educazione interculturale alla cittadinanza. Roma, Carocci, 29-34.

CAMilleRI, C. (1985) Antropología cultural y educación. París, Unesco.

Carrasco, S. (2004) Interculturalidad, educación, comunicación. Consultado el 17 de enero de 2011. http://www.blues.uab.es/incom/2004/cas/carrcas.html.

CASANOVA, M. A. (2005) La interculturalidad como factor de calidad educativa, en SoRIANO, E. (coord.) La interculturalidad como factor de calidad educativa. Madrid, La Muralla, $19-41$.

Cavali-Sforza, L.; Menozi, P. y Piazza, A. (1995) The History and Geography of Human Genes. Princenton, University Press.

Colectivo IOE (1998) Inmigración y diversidad social en la España de fin de siglo. Documentación social, 11, 233-248.

- (2008) Exploraciones de los discursos de la población inmigrante en España. Madrid, CIs.

- (2009) La condición inmigrante en España. Posiciones básicas en torno a la ciudadanía. Papeles de Relaciones Ecosociales y Cambio Global, 104, 23-37.

Cuché, D. (1999) La noción de cultura en ciencias sociales. Buenos Aires, Nueva visión.

DeCRETO 359/2009, de 30 de octubre por el que se establece y regula la respuesta educativa a la diversidad del alumnado en la Comunidad Autónoma de la Región de Murcia.

Dusi, P. (2009) Il conflicto. Uno sguardo pedagogico. Pedagogía e Vita, 3-4, 128-144.

ECO, U. (1998) Cinco escritos morales. Barcelona, Lumen.

ELIOT, T. S. (2003) La unidad de la cultura europea. Notas para la definición de la cultura. Madrid, Encuentros.

Escarbajal Frutos, A. (2009) Educadores, Trabajadores sociales e interculturalidad. Madrid, Dykinson.

Essomba, M. A. (2005) Perspectiva crítica de identidad y diversidad: creando entornos interculturales para la inclusión, en SORIANO, E. (coord.) La interculturalidad como factor de calidad educativa. Madrid, La Muralla, 119-130.

Galino, A. y EsCRIBANO, A. (1990) La educación intercultural en el enfoque y desarrollo del currículo. Madrid: Narcea.

García, A. (2004) La construcción sociocultural del racismo. Análisis y perspectivas. Madrid, Dykinson.

García, A.; Escarbajal Frutos, A. y Escarbajal de Haro, A. (2007) La interculturalidad. Desafío para la educación. Madrid, Dykinson. 
Genovese, A. (2003) Per una pedagogía interculturale. Bolonia, Universitá degli Studi.

GIDDENS, A. (2000) Il mondo che cambia. Come la globalizzazione ridisegna la nostra vita. Bologna, Il Mulino.

Gimeno, J. (1992) Currículum y diversidad cultural. Educación y Sociedad, 11, 127-153.

Gombrich, E. H. (2004) Breve historia de la cultura. Barcelona, Península.

Gould, S. J. (2007) La falsa medida del hombre. Barcelona, Drakontos.

HobsBawm, E. (2000) La izquierda y la política de la identidad. New Left Review, 0, 114-119.

Huntington, S. (1996) El choque de civilizaciones y la reconfiguración del orden mundial. Buenos Aires, Paidós.

Jiménez, R. y Aguado, T. (2002) Pedagogía de la diversidad. Madrid, uned.

Kroeber, L. y Cluckhoholm, C. (1952) Culture: A Critical Revision of Definitions and Concepts. Papers of The Peabody Museum of American Archaeology and Ethnology, 1 (47), 270-285.

Legrain, P. (2008) Inmigrantes. Tu país los necesita. Barcelona, Intermón-Oxfam Editorial.

Luhmann, N. (1997) La cultura como un concepto histórico. Historia y Grafía, 8, 1-12.

MAAlouf, A. (2008) Identidades asesinas. Madrid, Alianza.

Malinowski, B. (1981) Una teoría científica de la cultura. Barcelona, Edhasa.

Mantovani, G.; Schiavinato, V. y CotTone, P. (2006) Comprendere le differenze: l'influenza di concesión diverse della "cultura", en PORTERA, A. (a cura di) Educazione interculturale nel contesto internazionale. Milano, Angelo Guerini.

MarCaSe, H. (1970) Notas para una nueva definición de la cultura. Madrid, Ariel.

MARí, R. (1999) Educación multicultural y derecho a la diferencia. ¿Una propuesta ambigua?

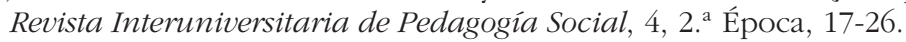

Marín, M. A. (2005) La construcción de identidades cívicas y culturales en la sociedad real, en SORIANO, E. (coord.) La interculturalidad como factor de calidad educativa. Madrid, La Muralla, 133-174.

Ministerio de Trabajo E InMigración (2010) Extranjeros residentes en España. Consultado el 2 de marzo de 2011. http://extranjeros.mtin.es/es/InformacionEstadistica/Informes/ Extranjeros31Diciembre2010/Archivos/Principales_Resultados_31122010.pdf.

MOsTerín, J. (2009) La cultura humana. Madrid, Espasa-Calpe.

NAÏr, S. (2006) Y vendrán... La inmigración en tiempos hostiles. Madrid, Planeta.

- (2010) La Europa mestiza. Inmigración, ciudadanía, codesarrollo. Barcelona, Galaxia Gutenberg-Círculo de Lectores.

ONU (2001) Conferencia de examen de Durban. Durban (Sudáfrica).

- (2009) Segunda conferencia de la ONU sobre el racismo. Ginebra (Suiza).

ORDEN de 20 de febrero de 2006, de la Consejería de Educación y Cultura, por la que se establecen medidas relativas a la mejora de la convivencia escolar en los centros docentes sostenidos con fondos públicos que imparten enseñanzas escolares.

ORDEN de 26 de julio de 2011, de la Consejería de Educación, Formación y Empleo, por la que se establece el programa "Planes para la mejora del éxito escolar y la participación educativa" y se regulan las bases para su implantación y desarrollo en los centros docentes públicos y privados concertados de la Región de Murcia.

Ortega, P.; Mínguez, R. y GiL, R. (1996) Valores y educación. Barcelona: Ariel.

PÉREZ DE CUÉlLAR, J. et al. (1997) Nuestra diversidad creativa. Madrid, SM.

Portera, A.; Dusi, P. y GuidetTi, B. (2010) L'educazione interculturale alla cittadinanza. Roma, Carocci.

René, G. (2006) Los orígenes de la cultura. Madrid, Trotta. 
SAN Román, B. (2008) ¿Por qué somos racistas? Magazine El País, 22, 6.

SÁNCHEZ, M. y ORdóÑEZ, M. J. (1997) La educación en la sociedad multicultural. Papers, 53, 139-148.

SANTERito, M. (2009) Vivere nel pluralismo. L'educazione alla cittadinanza in prospectiva interculturale. Consultado el 2 de marzo de 2011. http://www.indire.It.

SEn, A. (2007) Identidad y violencia: la ilusión del destino. Madrid, Katz Barpal.

Silva, C. (2008) Pedagogía, intercultura, diritti umani. Roma, Carocci.

TÉllez, J. A.; MáliK, B.; Mata, P. y Sutil, I. (2005) Orientación intercultural. Madrid, Sanz y Torres.

Todorov, T. (2008) El miedo a los bárbaros. Barcelona, Círculo de Lectores-Galaxia Gutenberg.

TYLor, E. B. (1871) Primitive Culture. Londres, John Murray. Consultado el 6 de diciembre de 2006. http://www.filosofía.org/filomat.htm. También puede consultarse esta obra en Tylor, E. B. (1995) La ciencia de la cultura, en KAHN, J. S. (coord.) El concepto de cultura. Barcelona, Anagrama, 29-46.

unESCO (1982) Conferencia Mundial sobre las Politicas Culturales. México.

- (1998) Conferencia Intergubernamental sobre Políticas Culturales para el Desarrollo. Estocolmo.

- (2003) Aprender a vivir juntos: ¿Hemos fracasado? Ginebra, Oficina Internacional de Educación.

Vidal-Beneyto, J. (2008) Más allá del "todo negocio". El País, 14 de junio.

VIEVIORKa, M. (2009) L'inquietudine delle differenze. Milano, Mondadori.

Vila, I.; Esteban, M. y Oller, J. (2010) Identidad nacional, lengua y escuela. Revista de Educación, 353, 39-65.

White, L. (1992) La energía y la evolución de la cultura, en Bohanann, P. y Glazer, M. (coords.) Antropología. Lecturas. Madrid, McGraw-Hill, 349-368.

Wolton, D. (2004a) La cohabitación de la diversidad. Babelia-El País, 8 de mayo.

- (2004b) La otra mundialización. Barcelona, Gedisa.

ZAMOrA, J. A. (2006) La inseguridad como ideología, la seguridad como chantaje. IgViv, 226, $35-44$. 